\title{
Trump and the Media. \\ Pablo J. Boczkowski y Zizi Papacharissi. Massachusetts: The Massachusetts Institute of Technology Press, 2018
}

\author{
Julia Evangelina Velisone \\ Carrera de Sociología, Facultad de Ciencias Sociales, Universidad de Buenos Aires, Argentina \\ jvelisone@sociales.uba.ar \\ https://orcid.org/0000-0003-1770-9844
}

La llegada de Donald J. Trump a la presidencia de Estados Unidos tomó a amplios sectores por sorpresa y suscitó diversos debates al respecto, enmarcados en el ascenso de líderes outsiders a la política en el plano mundial. Sin embargo, dos ideas han emergido con significativo consenso en Estados Unidos. Por un lado, la singularidad de la victoria electoral de Trump en el contexto del sistema político norteamericano. Por otra parte, la sensación de centralidad de los medios, desde las redes sociales hasta las empresas de noticias, en el desenvolvimiento de dichos hechos. A partir de lo expuesto, Pablo J. Boczkowski y Zizi Papacharissi recopilaron artículos de especialistas en comunicación, tecnología y política, con el objetivo de echar luz sobre los aspectos claves del ascenso de Trump en articulación con las dinámicas de la producción, distribución y recepción de noticias, y de las redes sociales. En palabras de los propios autores: "This book was born from the premise that these two ideas are connected, and that probing that connection provides a powerful window into broader transformations that mark the information landscape of the twenty-first century" (p. 2).

En consonancia con el objetivo anterior, en la parte introductoria del libro los editores resaltan tres temas centrales que vinculan los diferentes artículos. En un primer punto, desde un enfoque histórico analizan la situación actual del periodismo, así como el desarrollo de las redes sociales y sus usos en comunicación política. En este sentido, el proceso de orientación comercial de las instituciones de periodismo norteamericano dado en el siglo xx preparó el terreno para un sistema de noticias y redes sociales enfocado en el rédito económico e incapaz de contener la propagación de información falsa. En segundo lugar, es resaltada la preexistente situación de crisis que atravesaba el periodismo al momento de afrontar el creciente lugar de las redes sociales en la comunicación de información. En consecuencia, dicho oficio ya no detenta una posición monopólica como canal de vinculación entre el mundo político y el público, ni como canal de acceso a las noticias. Por último, las modificaciones en el mundo del periodismo son comprendidas dentro de una transformación social más vasta, siendo esta condición de posibilidad de la conexión entre el ascenso de Trump y las redes sociales. De esta forma, se denota el desarrollo de una cultura digital que combina el aumento de la concentración de poder en pocas corporaciones con el crecimiento de las capacidades de insurgencia distribuidas entre múltiples individuos y actores colectivos.

Luego de la introducción, el libro está organizado en cuatro secciones, contando con un total de 26 artículos de especialistas en diversas disciplinas. La primera parte, titulada "Journalism in Question" contiene siete artículos que estudian la posición actual del periodismo desde un enfoque histórico y el rol que juegan los medios a la hora de informar. El primer artículo presenta la continuidad, desde la época de la Guerra Fría, en el uso de un enemigo para la construcción de la identidad. En este sentido, Trump utiliza un discurso antiestablishment y contra los medios de comunicación, ante la sensación de fallos en ambos. Un segundo artículo trata sobre la transformación de 
los medios en relación con los datos "alternativos" dados por Trump, así como el uso de "fake news" como respaldo a sus posiciones. Luego, el tercer artículo explica la victoria de Trump en relación con los cambios discursivos, con tendencia antidemocrática. En este sentido, dentro de una nueva ecología de la comunicación pública, emergen la intolerancia, la incivilidad y las creencias fácticamente incorrectas como condicionantes. El cuarto artículo, analiza el rol del periodismo centrándose en tres cuestiones: los "filtros burbuja" dados por la exposición selectiva de noticias a los individuos según sus posiciones, la decadencia del periodismo profesional y la cultura de la posverdad. Ante lo cual, es posible el acercamiento del periodismo a la perspectiva de los ciudadanos, así como un enfoque emocional del mismo. Un quinto artículo, sitúa la victoria de Trump dentro del ascenso del populismo de derecha a nivel mundial y advierte sobre los peligros sobre los ideales de la democracia liberal. En este escenario, postula el lugar del periodismo, a partir de la renovación de su calidad, mediante la ética profesional y la corrección de sus informes. Por otra parte, el sexto artículo estudia la manipulación de los medios en la era de Trump, posibilitada por la crisis financiera y de legitimidad que atraviesa al periodismo. Dicha época es caracterizada por nuevas formas de producir y popularizar noticias, gracias a la territorialidad online de los medios de información y la comunicación política. Por último, el séptimo artículo analiza la participación del fotoperiodismo y de los paparazis como canal de control de la sociedad sobre los políticos y sus actos.

Luego, la segunda sección, Ilamada "Emotion, Populism and Media Events", estudia en siete artículos dichos tres temas en relación a las plataformas de información y los procesos democráticos. Un primer artículo estudia la centralidad de los titulares en los medios como herramienta de atracción y popularidad creciente en la era de la tecnología. En un segundo artículo, se analiza el factor emocional del discurso de Trump, entendiéndolo como condición de posibilidad para la motivación y participación política y como canal para la creación de solidaridades. El autor alerta sobre las consecuencias negativas del régimen emocional de Trump que funciona mediante la activación política del enojo. Luego, el tercer artículo, echa luz sobre la centralidad de la creación de mitos y de sistemas de creencias, sobre la razón y los datos comprobables. El Ilamado de Trump: "Make America Great Again", encuentra en las redes sociales su canal de multiplicación, posibilitando formarse como mito estructurador. Por otra parte, el cuarto artículo hace hincapié en la base identitaria que posee la política como fenómeno, y en su refuerzo a través de los medios, sobre una función informativa de los mismos. El ascenso de Trump es entendido desde la búsqueda de renovación de la identidad blancacristiana y no desde la comprobación de datos. El quinto artículo, trata sobre el factor anticipatorio en la creación de noticias y la impredecibilidad de Trump que conllevó su manejo de los tiempos de los medios. En consecuencia, es requerida la adaptación de los periodistas a la situación expectante para conseguir una reapropiación de la fijación de la agenda. Por su parte, el sexto artículo analiza las proyecciones de los medios en relación a la elección de 2016, postulando su capacidad de movilización 0 desmovilización de múltiples actores. En este sentido, el discurso antiestablishment y antimedios podría conllevar su crecimiento gracias a las propias proyecciones en su contra por parte de quienes representan dichos sectores. Finalmente, el séptimo artículo analiza la aplicación de la noción de autoritarismo al gobierno, entendiéndola como inadecuada ya que no se han eliminado medios o partidos opositores, ni limitado las capacidades del Congreso.

La tercera parte, titulada "Why Technology Matters", contiene seis artículos que analizan el lugar de la tecnología en el periodismo, las redes sociales, y las estrategias de comunicación política. El primer artículo caracteriza el presente siglo en términos de "network solidarity", en continuidad de la solidaridad mecánica y orgánica durkheimiana. En consecuencia, el triunfo del individuo sobre la sociedad, tras la revolución cultural, postula a las redes sociales como creadoras de los nuevos lazos sociales necesarios en la actualidad. Un segundo artículo, analiza el quiebre de reglas de la campaña política y de la cobertura presidencial, realizado por Trump y los medios de comunicación. Si bien la forma de vinculación del primero para con los segundos ha sido exitosa en la campaña, a su 
entrada a la presidencia ha comenzado su fracaso. En esta línea de estudios, el tercer artículo se enfoca en el uso de la plataforma Twitter en términos políticos. En su origen, la misma planteaba la democratización de la comunicación, pero Trump pareciera haber canalizado la euforia por el autoritarismo en articulación con la descentralización y cercanía de la información. Asimismo, el cuarto artículo es dedicado al uso de Twitter, argumentando su vinculación con una retórica populista como causa de la victoria de Trump. En este sentido, es advertida la articulación de la condición de outsider de Trump, su construcción de un enemigo, y su dominio de la atención de los medios masivos de comunicación. Por su parte, el quinto artículo toma otra posición, entendiendo la victoria de Trump desde el plano socioeconómico del país. En este sentido, la inequidad económica y la actitud desfavorable hacia los inmigrantes, conllevaron a sectores de la clase trabajadora blanca a apoyarlo. Justamente, son estos sectores con poca conexión con las redes sociales que más se cierran a sus propias visiones. Por último, el sexto artículo se enfoca en la reconstrucción de la confianza en los medios. Actualmente, luego del avance en la cuantificación de datos y su disponibilidad, la relación de los medios con su audiencia requiere de canales de información respecto al proceso de creación de noticias.

Finalmente, la última sección llamada "Pathways Ahead", a través de seis artículos, echa luz sobre los caminos futuros exponiendo conceptualizaciones teóricas e involucrando resultados de investigaciones con acción participativa. En este sentido, el primer artículo explica el egocentrismo de los medios a partir de la asimilación del rédito económico a la valorización de sus reportajes. En consecuencia, la solución planteada para reconstruir la confianza es una orientación relacional, mediante un periodismo responsable y reflexivo. En consonancia, el segundo artículo plantea la implementación de redes con diversos grupos comunitarios para construir un periodismo basado en hechos y de confianza para los propios actores involucrados. Luego, el tercer artículo introduce la noción de sociedad de la desinformación, en donde se articula un electorado que consume noticias sensacionalistas y medios degradados sin comunicación informativa. A partir de lo expuesto, nuevas formas de periodismo son necesarias, incluyendo el involucramiento de la sociedad civil, así como la diversificación de la posesión de los medios. En un cuarto artículo, el periodismo, en la era de las "fake news", es entendido a partir de una pérdida de su pretensión de objetividad para transformarse en activista, defensor de la democracia. Con dicho objetivo, es requerido un periodismo independiente, basado en los hechos y de trabajo colectivo. Por su parte, el quinto artículo refiere al periodismo de campaña, es decir, al trabajo de reportar una problemática social por periodos prolongados en el tiempo con el objetivo de lograr una respuesta política de parte de la audiencia. Este tipo de periodismo proactivo posibilitaría volver a marcar la agenda pública en relación a las noticias de mayor impacto. Finalmente, el último artículo analiza los ataques de Trump hacia el periodismo como institución. En línea con las exposiciones previas, se propone una defensa conjunta de quienes se involucran en dicho "cuarto estado" para lograr una prensa libre y funcional.

A través lo expuesto los autores se insertan en el campo de investigación del periodismo y su relación con la política, postulando articulaciones multiescalares y nuevos interrogantes para futuros trabajos. El libro reseñado consigue sus objetivos expuestos y ofrece un marco de análisis para una mayor comprensión de diversas realidades. A partir de dicho análisis es posible una reflexión de mayor profundidad de los cambios en la política actual en articulación con las redes sociales y las transformaciones en la comunicación. A modo de ejemplo, el contexto político de Argentina y el gobierno de Cambiemos, es reflejo local de modificaciones en el plano global, por lo que los artículos reseñados resultan puntapiés para estudios comparativos y reflexiones críticas desde la coyuntura Latinoamericana. 
